\title{
Disruptive Times, Disruptive Engineering, the Need for New Approaches for Disruptive Project Management
}

\author{
Geert Dewulf ${ }^{1}$
}

\section{Keywords}

project management; uncertainties, flexibility, adaptive approach

The bulk of literature on project management is prescriptive and considers projects as linear processes with the premise that a good and wellthought design will lead to the expected goals. This is based on the paradigm of reductionism which dominated science for centuries. In short, reductionists argue that further study of the parts of systems will lead to deeper understanding and predictability (Capra, 1996). Reductionist thinking has also been applied in organisation science. Taylor for instance believed that if workers would do their work in the "one best way," everyone would benefit (Kanigel, 1997). Taylorism resulted in huge gains in productivity through the introduction of scientific study of time and motion in work. These ideas form a deeply held paradigm today (Brown and Eisenhardt, 1998; Morgan, 1997).

The paradigm of reductionism pays little attention at how to deal with disruptions or unforeseen events. There is, however, a strong need for management tools that enable project managers to deal with uncertainty and to cope with unforeseen challenges. Disruptions as the COVID-19 pandemic made clear ask for a research agenda to understand the impact of periods of disorder on the organisation of engineering projects. In disruptive times, rational approaches and traditional engineering or project management measures no longer work. This paper is a plea for new approaches for disruptive project management and discusses ways to cope in disruptive times.

Many studies address how technologies will change industry and our daily life in a drastic or disruptive way. For instance, Eck (2020) expects that the fourth industrial revolution and the technological changes implemented will disrupt entire industries. The advent of technologies such as cryptocurrencies, blockchain, adaptive and predictive algorithms and the use of big data would change the industry.

This paper does, however, not focus on the impact of technologies on society, rather it tries to explain what enables the implementation of disruptive innovations and what impact these disruptions have on the way we organise engineering projects. Disruptive times may even lead to an acceleration of the implementation of disruptive innovations. Disruptive times not only require new technologies, disruptions ask for new ways of managing projects. However, most project managers were trained to make proper analyses, predict the outcomes and use means to meet the project goals. Project management handbooks are based on the philosophy of Laplace, Laplace (1902). ${ }^{1}$ His basic belief is that, if we are able to identify the conditions of events, we can predict accurately the future. This became known as the Laplace's Demon, the idea of physical determinism with one possible future. Due to the growing

\footnotetext{
${ }^{1}$ Laplace in S.M. Stigler (2005) P.S. Laplace, Theorie analytique des probabilities, first edition (1812); Essai philosophique sur les probabilities, first edition (1814). Grattan-Guinness, I., Cooke, R., Carry, L., Crepel, P., Guicciardini, N. (2005). Landmark Writings in Western Mathematics, pp. 1640-1940.
}

\footnotetext{
${ }^{1}$ *University of Twente, Enschede, the Netherlands, g.p.m.r.dewulf@utwente.nl (Corresponding Author)
} 
complexity and uncertainty, there is a need for a new approach or, in the terminology of Marchau et al. (2019), the increasing uncertainty asks for a 'monitor and adapt' paradigm instead of a 'predict then act' paradigm.

In the next section, we elaborate on how disruptive times accelerate the implementation of new technologies. In the second section, we discuss a new paradigm for engineering project organization research. Finally, we discuss various implications for the research on engineering project organizations.

\section{Disruptive Times as Accelerator of Disruptive Innovations}

Christensen et al., 2018 explains how disruptive innovation transforms existing markets. Disruptive innovation starts in a niche market that may appear unattractive to existing industries but eventually transforms this industry. Christensen et al. refer to the personal computer and cellular phones as clear examples of disruptive innovation. The current pandemic shows how the implementation of disruptive innovations have been accelerated. COVID-19 has unprecedented implications for companies and societies worldwide and companies have neither prepared for it nor have they planned to transition beyond the pandemic. (Rowan and Galanakis, 2020).

The pandemic certainly led to an acceleration of the implementation of new technologies in our daily social and work life. We suddenly work and lecture in a very different way. The use of technologies, by children and elderly, can now be seen everywhere in the world. The digitization of society became reality. In their comprehensive book on The Disruptive Fourth Industrial Revolution published this year - written before the pandemic - Doorsamy et al. (2020) foresaw that the limited empowered public or industry workforce with relatively low technical skills and digital literacy would cause a major problem for the implementation of $\mathrm{AI}$ in governments and industries. And although much still can be improved, COVID-19 pushed forward the digital literacy in an unprecedented way.

Various studies (Ansari et al., 2016; Si et al., 2020) have shown that take actions first to adopt technologies that become dominant later on usually survive and prosper. For companies, disruptive innovation and disruptive entrepreneurship are seen as a strategic means for achieving sustainable growth and competitiveness but we can use a parallel with countries or systems.

History has shown that not only industries but also countries survive if they adapt quickly to changing circumstances. In his magnificent book the Olson (1982) linked stability or disorder to economic growth. He reasoned that countries which have experienced prolonged periods of disorder or armed conflicts will have lower numbers of interest groups or collusion organisations. On the other hand, stable countries tend to become protectionistic and are less eager to change.

Following this rationale, it implies that instability is often an enabler of change - or in the context of this paper - a disruptive time is needed for a fast implementation of disruptive technologies. Perhaps the current pandemic helps us to reshape our societal agenda. We now already see, besides a fast adaptation of technologies, a renewed enthusiasm about sustainability issues. Due to distant learning, working at home and other developments we realised that a new and more sustainable lifestyle is possible and perhaps easier to attain than we expected. Students all over the world are pushing their boards to implement sustainability goals, local organic farms are becoming popular and even policy makers from left to right are now promoting sustainability policies.

Another key change due to the pandemic is the rapid digitization of the health sector. Due to COVID-19, patients were not able to meet their doctor physically. E-health created a solution. Through video calling and remote contacts the physician is now able to connect with his or her patients, make an accurate diagnosis, and advise and start treatments. Moreover, AI provides new insight leading to quick responses and a more integrated diagnosis of the health conditions of a patient. The use of virtual and augmented reality in surgery enables a more efficient and safe invasive medical treatment. Besides the health sector, the accelerated implementation of $\mathrm{AI}$ is visible in 
many other domains for instance in e-government, in distance education and e-commerce.

But the fast development of one disruptive innovation has a multiplying effect on other societal and technological developments, often due to negative by-effects. The growing AI dependency has led to concerns about the growing energy demand and security issues. And, moreover, the growing demand for energy further stimulates the demand for AI solutions the so-called smart grids or digital transformation of the grids. ${ }^{2}$

For instance, the energy consumption of a data centre of Google in the Netherlands equals the amount half a million households needs. Many countries are now investing in experimental technologies as heat recovery, AI solutions, photonics-based components, and neuromorphic computing. Besides, Western countries are confronted with outdated grid structures. Grids and infrastructure in general are desperately in need of repair and increasingly so since they are subject to weather disruptions due to climate change (Kiatkowski et al., 2020). Another challenge of the fast digitization is how to govern cybersecurity. In recent years, we have seen the major impact cyberattacks might have.

What these examples show is that the implementation of disruptive technologies and innovation lead to other societal challenges and that many of the disruptions are interrelated. But what also became clear is that disruptive times not only accelerated the use of disruptive technologies, disruptive behaviour is also needed. Technology without behaviour change won't work.

\section{Disruptive Times, the Plea for a New Project Management Paradigm}

COVID-19 devastated our social life and hampered economic growth. 2020 can be characterised as

\footnotetext{
${ }^{2}$ (see Smart, Green Grids, The Green industrial revolution, 2015; chapter 8 , http: //dx.doi.org/10.1016/ B978-0-12-802314-3.00008-1)
}

a year of disruptions. A disruptive time is a very uncertain period, a period where we cannot simply rely on historical data and past knowledge to find solutions. It is a period of 'deep uncertainty' (Walker et al., 2019). When changes are characterised by a high degree of uncertainty, Marchau et al. (2019) consider the resulting situation to be "deeply uncertain". This is a situation in which the experts or decision-makers cannot agree upon "(1) the appropriate models to describe the interactions among a system's variables, (2) the probability distributions to represent uncertainty about key variables and parameters in the models, and/or (3) how to value the desirability of alternative outcomes.

A deep uncertain event is what Taleb (2007) calls a black swan. A black swan lies outside the realm of regular expectations, carries an extreme impact and is only explainable after the event occurred. All project managers in the engineering domain have learnt in a hard way that wellthought-out plans and designs are no guarantee for success later on.

The uncertain times and the related introduction of disruptive technologies have far-reaching consequences for how engineering projects are organised and the way they are managed. In many project management papers and publications in the field of Public Administration, the focus is on KPIs and handbooks are traditionally based on the assumption that the world is predictable. Project managers are trained to start with a proper analysis often based on historical data, we design, predict, test and evaluate.

Poincare (1913) already pinpointed a century ago that small errors of the present may lead to big errors in our future predictions. Still today, it is generally argued that, since our prediction models tend to become more and more sophisticated and complex, we are able to foresee the future and can assess the impacts of today's decision.

But, in his marvellous article published in 1968 with the title 'Predicting Best with Imperfect Data' William Allonso (Alonso, 1968) stated that the most elaborate and inclusive predictive models are not necessarily the best. This may be the case if the cumulation of data errors exceeds the predictive gain from superior specification, a 
stage which ambitious models may have reached. He elaborates further by stating that the Rules of Thumb for choosing and building models by this criterion suggests that, when complication leads to negative returns, a strategy of netting out simple, complementary models may be better. Related, a study of Dewulf (1990) on prediction models concluded that in times where there is a clear turning-point (what I would call now a disruptive time) forecasts are more accurate if they rely on theoretical insights or judgments rather than on historical data and past experience. For many scientists, this is difficult to accept.

In a disruptive period, as the pandemic shows, project engineers have to deal with many uncertainties and cannot rely on past experience and historical data. Consequently, the outcomes of projects are less predictable. Project engineers and scholars should be aware that planning processes and projects in general do not neatly follow a sequence of well-defined steps (Bishop, 1998).

This generates major challenges for projects. Before large scale projects are publicly procured, governments set baseline predictions regarding for instance traffic flows, economic developments and the environment. Such procured projects are Public Private Partnerships which are based on risk transfer models(Dewulf et al., 2016). Risks are priced and transferred to a private consortium. Risks are however assessed on historical grounds and the risk models form the basis for the long term, often 30 years, contract. Of course, all PPP contracts contain a section on how to deal with unforeseen events or 'force majeure' situations. Once the consortium does not fulfil its obligations, the contract might be dissolved by the government. In practice, however, this is not possible due to a typical locked-in situation. In many cases, dissolving a contract would have a tremendous impact on the unemployment numbers and in general on the economy. Hence, how to deal with uncertainties and, moreover, how to manage unforeseen events should be one of the leading topics in project organisation research. To be able to cope with unforeseen events and manage uncertainties, we should choose for a more adaptive approach and define adaptive pathways when managing projects.

\section{Impact on the Research} Agenda on Engineering Project Organizations

In general, most studies in the field of Engineering Project Organisation focus on controlling risks rather than coping with uncertainties. Some work has explored topics such as renegotiation and contractual design as ways to address lifecycle uncertainty (Athias and Saussier, 2007) as well as counterparty actions during project implementation and operations (Chung and Hensher, 2015). Addressing uncertainty through strategies such as adaptation and learning, however, is not prevalent in literature even though changes in project, political and macro environments are likely. Large projects, and especially PPPs, evolve during the life cycle of projects and stakeholder network changes. (South et al., 2015). We can learn from other domains as Urban Planning, Public Administration and Strategic Management where recently there is a growing number of publications on adaptive management approaches to cope with uncertainty. These new insights offer directions for engineering project research.

Adaptive governance is one theoretical concept discussed in recent Public Administration literature. 'Adaptive governance' theory emphasises the importance of learning (in projects) and coproduction between stakeholders for designing solutions for today's problems. (Dewulf and Garvin, 2020) The uncertainty we have to deal with requires more flexibility and adaptability to specific circumstances in our project organisations. Dealing with an uncertain context has been a subject of debate in planning and governance practice and literature in recent years where institutions are often perceived as rigid fixtures, which usually hinder solutions to planning problems (see for instance Dembski and Salet, 2010). Rules and procedures are often very restrictive and limit the opportunities to find creative solutions that meet the requirements of a specific situation (Zonneveld et al., 2011). Project managers traditionally tend to believe they have a basis to solicit competitive fixed-price bids from the supply-chain of specialised contractors for 
providing required goods or services in a project. Levitt (2011) emphasised that due to changing perspectives of (sub-) contractors and conflicting sub-goals that evolve within each group over time, misalignment of goals may emerge. Traditional project management approaches does not take these changes into account.

In our daily practice of studying project organisations we see the impact of not responding or responding too late to unforeseen events. During the operation phase, functional changes not foreseen at the time of contract formation may result in pitfalls, such as delays due to unclear responsibilities, discussion of prices, and other claims. Levitt (2011) plea for more agile methods in project management due to the fast changing and unpredictable environment fits in this debate. Levitt calls this Project Management 2.0 which requires other project planning tools and different competencies based on relational contracting that exploits psychological and sociological mechanisms, such as developing a shared identity for all stakeholders involved in the project.

Related to adaptive governance is the concept of dynamic adaptive planning which focuses on the implementation of an initial plan to the resolution of major uncertainties with the plan being adapted over time based on new knowledge. This approach makes adaptation over time explicit. Walker et al. (2019) defines two steps. The first step is the design phase, in which the adaptive plan, monitoring plan and various actions are designed. Second comes the implementation phase, in which the plan and the monitoring programme are implemented and contingent actions are taken. It is, therefore, important to make explicit under what conditions a plan might fail. Haasnoot et al. (2013) call this Adaptation Tipping Points. For these points, contract partners should define alternative routes into the future.

Rauws and De Roo (2016) mention that adaptive planning is a shift in focus from content and process to more focus on creating conditions for development which support a city (or region) to respond to changing circumstances. Certainly, in large scale engineering projects with a long term contract we should before and during the project think about how to deal with contingencies. Large scale and long-term projects as PPPs often have to adjust contracts due to changing circumstances. Consequently, contractors define in the contract clauses to deal with these events. The UK Highways Agency for instance defines conditions for a 'contract review' to be able to anticipate unexpected events and to provide a structure for adjustment (Dewulf and Garvin, 2020). Formal and informal mechanisms can be used to cope in these situations but these mechanisms are intertwined and reinforce each other (Benítez-Ávila et al., 2018). Within projects, various studies have looked into the role of relational mechanisms to cope with unforeseen events. One such a mechanism is trust needed to offset the opportunity costs of deviating from contract conditions when conflicts occur (Benitez-Avila, Hartmann and Dewulf, 2019). However, relational mechanisms change over time. Project managers have to consistently adjust established relational approaches to respond to unforeseen events in complex project organisations as PPPs.

Another lens to deal with flexibility and adaptability in engineering projects offers the real option theory which has become today an indispensable element of corporate strategic decision-making (Rózsa, 2016). In strategic management journals multiple papers have been published on real options and what opportunities real option theory offers for strategic decisionmaking (Trigeorgis and Reuer, 2017). Chiara et al. (2007) used this theory for addressing risk management options in infrastructure projects. Shan et al. (2010) studied revenue guarantee options as means of managing revenue risks in PPP contracts. The use of real options is related to what Neufville and Scholtes (2011) call Engineering Project Analysis which refers to the process of assigning economic value to technical flexibility.

Relational mechanisms or participatory processes are often seen as ways to deal with the dynamics in engineering projects and networks, although many project managers may proclaim that disruptions should be handled in a top-down. It might be argued that participatory and collaborative processes hamper quick and efficient responses to conflicts and crises. However, engagement of all stakeholders is needed for disruptive engineering 
and implementation of disruptive innovations. A good example can be found in a paper of Huisman (2014) on the role of participation in displacements projects. She studied how participatory meetings helped to avoid resistance in urban projects where tenants have to leave their beloved houses. This was the case for 10000 householders during a period of five years in Amsterdam. The formal participatory framework shaped and even limited the tenants' space for action. No participation would have led to resistance. Participation led to the contrary. It helped to steer the action in a certain direction. Huisman (2014) concluded, is then not used to reach consensus but as a technique of governmentality. In general, engagement of stakeholders should be a primary concern in large projects as PPPs (South et al., 2015). Moreover, participation is also meant to develop legitimacy and strengthen commitment for the policies that follow, and build trust and realistic expectations (Connelly et al., 2006).

\section{Final Remark}

COVID-19 pandemic has a huge impact on our daily life. People all over the world are struggling with the uncertain future. The paper revealed the need for new approaches for disruptive project management. Consequently, there is a growing demand for groundbreaking research on how to manage or organise engineering projects in disruptive times. This paper does not provide an extensive overview of possible directions for research. It merely discusses several interesting lenses which could help researchers in addressing this topic. The biggest challenge for researchers in the domain of Engineering Project Organisations is the shift in mindset. A change is required from a 'predict and control' paradigm to a 'monitor and adapt' one.

Today, more than ever, engineers are needed to design solutions. The uncertain future also generates opportunities and society is asking for an engineering mindset. Or in the words of Madhavan (2016) in his smart and fascinating book 'Think like an engineer': Engineers transform problems into opportunities!

\section{References}

Alonso, W. (1968), "Predicting best with imperfect data", Journal of the American Institute of Planners, Vol. 34 No. 4, pp. 248-255. 10.1080/01944366808977813

Ansari, S.S., Garud, R. and Kumaraswamy, A. (2016), "The disruptor's dilemma: TiVo and the U.S. television ecosystem", Strategic Management Journal, Vol. 37 No. 9, pp. 1829-1853. 10.1002/smj.2442

Benitez-Avila, Hartmann, A. and Dewulf, G. (2019), "Contractual and relational governance as Positioned-Practices in ongoing public-private partnership projects", Project Management Journal, Vol. 50. ( No. 6, pp. 716-733.

Athias, L. and Saussier, S. (2007), "Contractual flexibility or rigidity for public private partnerships? Theory and evidence from infrastructure concession contracts (MPRA Paper No. 10541)", available at: https://papers.ssrn.com/ sol3/papers.cfm?abstract $\mathrm{id}=828944$.

. and Benítez-Ávila, C., Hartmann, A., Dewulf, G. and Henseler, J. (2018), "Interplay of relational and contractual governance in public-private partnerships: The mediating role of relational norms, trust and partners' contribution", International Journal of Project Management No., Vol. 36 No. 3, pp. 429-443. 10.1016/j.ijproman.2017.12.005

Bishop, I.D. (1998), "Planning support: hardware and software in search of a system", Computers, Environment and Urban Systems, Vol. 22 No. 3, pp. 189-202. 10.1016/S0198-9715(98)00047-7

Brown, S.L. and Eisenhardt, K.M. (1998), “Competing on the Edge: Strategy as Structured Chaos, Harvard Business Press", Oxford.

Capra, F. (1996), The Web of Life: A New Scientific Understanding of Living Systems. New York City: Anchor Books.

Chiara, N., Garvin, M.J. and Vecer, J. (2007), "Valuing simple Multiple-Exercise real options in infrastructure projects", Journal of Infrastructure Systems, Vol. 13 No. 2, pp. 97-104. 10.1061/(ASCE)10760342(2007)13:2(97)

Christensen, C.M., McDonald, R., Altman, E.J. and Palmer, J.E. (2018), "Disruptive innovation: an intellectual history and directions for future research", Journal of Management Studies, Vol. 55 No. 7 , 1043. 1043-1078. 10.1111/joms.12349

Chung, D. and Hensher, D. (2015), "Risk management in public-private partnerships", Australian Accounting Review, Vol. 25 No. 1, pp. 13-27. 10.1111/ auar. 12062 
Connelly, S., Richardson, T. and Miles, T. (2006), "Situated legitimacy: Deliberative arenas and the new rural governance", Journal of Rural Studies, Vol. 22 No. 3, pp. 267-277. 10.1016/j. jrurstud.2005.11.008

Dembski, S. and Salet, W. (2010), "The transformative potential of institutions: how symbolic markers can Institute new social meaning in changing cities", Environment and Planning A: Economy and Space, Vol. 42 No. 3, pp. 611-625. 10.1068/a42184

Dewulf, G. (1990), Limits to Forecastingforecasting (Thesis). Utrecht: University of Utrecht.

Dewulf, G. and Garvin, M.J. (2020), "Responsive governance in ppp projects to manage uncertainty", Construction Management and Economics, Vol. 38 No. 4, pp. 383-397. 10.1080/01446193.2019.1618478

Dewulf, G., Garvin, M.J. and Duffield, C. (2016), "Multinational comparison of the tension between standards and context in PPP". In: Romboutsos A, ed, Public private partnerships in transport: trends and theory. New York, NY: Routledge Studies in Transport Analysis. pp. 267-291.

Doorsamy, W., Paul, B.S. and Marwala, T. (2020), The Disruptive Fourth Industrial Revolution; Technology, Society and Beyond. vol. 674. Berlin, Germany: Springer.

Eck, M.Mvan. (2020), "The disruptive Force of Smart Contracts". In: Paul B. S, Marwala T, Doorsamy W, eds, The Disruptive Fourth Industrial Revolution; Technology, Society and Beyond. vol. 674. Berlin, Germany: Springer. pp. 21-46.

Haasnoot, M., Kwakkel, J.H., Walker, W.E. and ter Maat, J. (2013), "Dynamic adaptive policy pathways: a method for crafting robust decisions for a deeply uncertain world", Global Environmental Change, Vol. 23 No. 2, pp. 485-498. 10.1016/j. gloenvcha.2012.12.006

Huisman, C. (2014), "Displacement through participation", Tijdschrift voor Economische en Sociale Geografie No., Vol. 105 No. 2, pp. 161-174. 10.1111/ tesg. 12048

Kanigel, R. (1997), Taylor-made, The Sciences. vol. 37, 3 ed. New York: New York Academy of Sciences.

. and Kiatkowski, K.P., Stipanovic, I., Maat, Hter., Hartmann, A., Chinowsky, P. and Dewulf, G. (2020), "Modeling cost impacts and adaptation of Freeze-Taw climate change on a porous asphalt road network", Journal of Instrastructure Systems No., Vol. 26 No. 3.

Laplace. (1902), A Philosophical Essay. New York: .
Levitt, R.E. (2011), "Towards project management 2.0", Engineering Project Organization Journal, Vol. 1 No. 3, pp. 197-210. 10.1080/21573727.2011.609558

Madhavan, G. (2016), Think like an Engineer. Inside the minds that are changing our lives. London: Oneworld publications.

Marchau, V.A.W.J., Walker, W.E., Bloemen, P.J.T.M. and Popper, S.W. (2019), Decision Making under Deep Uncertainty from Theory to Practice. Cham, Switzerland: Springer.

Morgan, D.L. (1997), Focus groups as qualitative research. 2nd ed. Thousand Oaks: Sage.

Neufville, Rde. and Scholtes, S. (2011), Flexibility in Engineering Design. Cambridge: The MIT Press.

Olson, M. (1982), The rise and decline of nations: economic growth, Stagflation and social Rigidities. New Haven, CO: Yale University Press.

Poincare, H. (1913), The Foundations of Science. Science and Hypothesis. The Value of Science. Science and Method. The. New York: Science Press.

Rauws, W. and De Roo, G. (2016), “Adaptive planning: generating conditions for urban adaptability. lessons from Dutch organic development strategies", Environment and Planning B: Planning and Design, Vol. 43 No. 6, pp. 1052-1074. $10.1177 / 0265813516658886$

Rowan, N.J. and Galanakis, C.M. (2020), "Unlocking challenges and opportunities presented by COVID-19 pandemic for cross-cutting disruption in agri-food and green deal innovations: quo vadis?" Science of The Total Environment, Vol. 748 No. 1, p. 141362. 10.1016/j.scitotenv.2020.141362

Rózsa, A. (2016), "Development of real option theory in the last 20 years", Economic Sciences No., Vol. 25 No. 1, pp. 698-709.

Shan, L., Garvin, M.J. and Kumar, R. (2010), "Collar options to manage revenue risks in real Toll public-private partnership transportation projects", Construction Management and Economics, Vol. 28 No. 10, pp. 1057-1069. 10.1080/01446193.2010.506645

Si, S., Zahra, S.A., Wu, X. and Jeng, D.J.-F. (2020), "Disruptive innovation and entrepreneurship in emerging economics", Journal of Engineering and Technology Management, Vol. 58 No. 8, 101601. 10.1016/j.jengtecman.2020.101601

South, A., Levitt, R.E. and Dewulf, G. (2015), “Dynamic Stakeholder Networks and the Governance of PPPs", The proceedings of the 2nd International Conference on Public-Private Partnerships (ICPPP 2015). 26-29. 
Taleb, N.N. (2007), The Black Swan: The Impact of the Highly Improbable. New York, USA: Random House.

Trigeorgis, L. and Reuer, J.J. (2017), "Real options theory in strategic management", Strategic Management Journal, Vol. 38 No. 1, pp. 42-63. 10.1002/ smj. 2593

Walker, W., Marchau, V.A.W.J. and Kwakkel, J.H. (2019), "Dynamic Adaptice Planning (DAP)". In:
Marchau V. A. W. J, Walker W. E, Bloemen P. J. T. M, Popper S. W, eds, Decision Making under Deep Uncertainty from Theory to Practice. Cham, Switzerland: Springer. pp. 53-69.

Zonneveld, W., Korthals Altes, W., Spaans, M., Waterhout, B. and de Wolff, H. (2011), Knelpunten gebiedsontwikkeling: de rol van Europese richtlijnen. OTB, Delft: Ministry of Economic Affairs. 